\title{
A Method of Calculating Total Respiratory System Compliance from Resonant Frequency: Validity in a Rabbit Model $^{1}$
}

\author{
ANDREAS SCHULZE, PETER SCHALLER, JÜRGEN DINGER, ULF WINKLER, AND \\ DIETER GMYREK \\ Children's Hospital, Department of Neonatology, and the Institute of Biomedical Engineering, Medical Academy \\ "Carl Gustav Carus," Dresden, East Germany
}

\begin{abstract}
Ten anesthetized, tracheotomized, adult rabbits were used to test the validity of a method for calculation of total respiratory system compliance from resonant frequency $\left(C_{r}\right)$. Reference values were obtained during constant flow inflation of the relaxed respiratory system by dividing the volume gain by the related difference in pressure at the airway opening (inflation method compliance, $C_{i}$ ). The animals were connected to a new type of servocontrolled infant ventilator. Besides volume-controlled mechanical ventilation at constant inspiratory flow rate and intermittent mandatory ventilation, there is a negative ventilator resistance mode integrated in this device for resistive unloading (Schulze A, Schaller P, Gehrhardt B, Mädler H-J, Gmyrek D: Pediatr Res 28:79-82, 1990). To measure resonant frequency $\left(f_{r}\right)$, the respiratory system was totally unloaded for a short period by a negative ventilator resistance exceeding the combined resistances of the endotracheal tube and airways. This evoked a continuous oscillation at $f_{r}$. By analogy with electrical circuit theory, $C_{r}$ was calculated according to $C=1 /\left(4 \pi^{2} \cdot I \cdot f_{r}^{2}\right)$ where $C$ is compliance and $I$ is inertance. The inertance of the endotracheal tube is given and that of the bronchial tree was ignored assuming a much greater total cross-sectional area and therefore much lower inertance when compared with the endotracheal tube. Three pairs of $C_{i}-C_{r}$ values were obtained from each animal: 1 ) during intact respiratory muscle activity; 2) after pancuronium relaxation, and 3) after surfactant depletion by saline washout. There was a significant linear correlation between $C_{i}$ and $C_{r}$ values with the regression line lying close to the identity line $\left(C_{r}=1.1\right.$ $\left.C_{i}-0.74 ; r=0.97 ; p<0.0001\right) . C_{i}$ increased from $45.3 \pm$ 9.4 to $47 \pm 7.1 \mathrm{~mL} / \mathrm{kPa}$ after pancuronium relaxation and dropped to $25.5 \pm 5.2$ after surfactant depletion. The corresponding $C_{r}$ values were $49.5 \pm 11,51 \pm 8.2$, and 27 $\pm 5.9 \mathrm{~mL} / \mathrm{kPa}$, respectively. The $\mathrm{f}_{\mathrm{r}}$ value decreased from $274 \pm 33.2 \mathrm{~min}^{-1}$ before to $267 \pm 21.4$ after relaxation, and was $371 \pm 39.5 \mathrm{~min}^{-1}$ after injury. (Pediatr Res 28: 599-602, 1990)
\end{abstract}

\section{Abbreviations}

$C_{i}$, total respiratory system compliance according to the inflation method

$C_{r}$, total respiratory system compliance according to the resonant frequency method

CMV, volume-controlled mechanical ventilation

Received February 1, 1990; accepted July 14, 1990.

Correspondence and reprint requests: Dr. sc. med. A Schulze, Medical Academy "Carl Gustav Carus," Children's Hospital, Dept. Neonatology, Fetscherstr. 74, Dresden 8019 , East Germany.

'Presented in part at the Annual Meeting of the European Society for Pediatric Research, Vienna, Austria 1990.
CPAP, continuous positive airway pressure ETT, endotracheal tube $f_{r}$, resonant frequency

$I$, inertance

NVR, negative ventilator resistance $P_{\text {ao }}$, pressure at the airway opening $\dot{\mathrm{V}}$, flow

The respiratory system can be modeled by an electrical circuit with resistor, capacitance, and inductor in series. In such a model, the resistor represents the resistance to gas flow, the capacitance is analogous to respiratory system compliance (C), and the inductor is the gas inertance (I). Such systems are characterized by an ability to swing at their $\mathrm{f}_{\mathrm{r}}$. According to electrical circuit theory,

$$
\mathrm{f}_{\mathrm{r}}=\frac{1}{2 \pi \sqrt{\mathrm{I} \cdot \mathrm{C}}}
$$

and therefore

$$
\mathrm{C}=\frac{1}{4 \pi^{2} \cdot \mathrm{I} \cdot \mathrm{f}_{\mathrm{r}}^{2}}
$$

Knowing $f_{r}$ and $I$, we can calculate $C$. The background for obtaining $f_{r}$ and $I$ is as follows.

Determination of $f_{r}$. Resistance dampens the tendency of the resistor-capacitance-inductor system to oscillate at resonance. Therefore, resistance must be compensated for or eliminated to induce a continuous oscillation. The total resistance of the combined patient-ETT-respirator system equals the sum of the resistances of all parts. The only way to decrease total resistance is therefore to use an NVR because the patient's and the ETT's resistances are given. We used a ventilator that has been specifically designed for infants with their narrow ETT (1-4). It is an all-purpose, valveless ventilator with an NVR mode for resistive unloading of the respiratory-ETT system. Thereby, resonant oscillation was induced and measured.

Calculation of $I$. I of a gas in a tube is defined by

$$
\mathrm{I}=\rho \cdot \frac{4 \cdot 1}{\pi \cdot \mathrm{d}^{2}}
$$

where $\rho$ is gas density and 1 and $\mathrm{d}$ are the length and diameter, respectively. Since the total cross-sectional area of the bronchial tree increases from central to peripheral parts of the lung (5) and the diameter's exponent in the denominator in equation 3 is 2 , it was assumed that the ETT constitutes the major I of the whole system. I of the bronchial tree was neglected. 
The aim of our study was to test the validity of this "resonant method" for determination of total respiratory system compliance (6) in a rabbit model. The "constant flow inflation method" of compliance measurement (7-9) was used for comparison.

\section{MATERIALS AND METHODS}

Ventilator. Transducers for $\mathrm{P}_{\mathrm{ao}}$ and $\dot{\mathrm{V}}(10,11)$ are mounted directly near the ETT adaptor. These sensors are components of two feedback loops for $\mathrm{P}_{\mathrm{ao}}$ and $\dot{\mathrm{V}}$, respectively. A microcomputer provides reference signals and switches one of the loops on-line while the other is off-line. To generate CMV, the $\dot{V}$ loop is online during the inspiratory part of the cycle. If a constant inspiratory $\dot{V}$ pattern is selected, the ventilator calculates $C_{i}$ using the quotient of volume gain $(\Delta \mathrm{V})$ and $\Delta \mathrm{P}_{\mathrm{ao}}$ in a time frame starting after $10 \%$ of total inflation time until end inflation. Volume is calculated as the integral of $\dot{V}$. To allow for exhalation against a preset constant expiratory $\mathrm{P}_{\mathrm{ao}}$, the ventilator is switched over to the pressure feedback loop. In the CPAP mode for spontaneous breathing, the pressure feedback loop is only used to maintain a constant $\mathrm{P}_{\mathrm{a} o}$. To introduce an NVR, the $\dot{\mathrm{V}}$ signal is additionally imposed on the error signal of the $\mathrm{P}_{\mathrm{ao}}$ controller in such a manner that an inspiratory flow increases and an expiratory flow decreases $P_{\text {ao }}$. Henceforth, there is a difference between the preset baseline $\mathrm{P}_{\mathrm{ao}}$ level and the instantaneous $\mathrm{P}_{\mathrm{a} o}$. The ratio $\Delta \mathrm{P}_{\mathrm{ao}}$ per $\dot{V}$ is constant at any moment. It has units of resistance $(\mathrm{kPa} \cdot \mathrm{s} /$ $\mathrm{L})$. An adjustable amplifier of the $\dot{\mathrm{V}}$ signal allows one to select the desired amount of NVR $(0-15 \mathrm{kPa} \cdot \mathrm{s} / \mathrm{L})$. NVR as used in this study was linear all over the $\dot{V}$ range. Against this, the positive resistance of the ETT and airways is nonlinear, i.e. it decreases with decreasing $\dot{V}$. Therefore, if the amount of NVR is increased, the total resistance of the combined lung-ETTventilator becomes negative over an increasing $\dot{V}$ range around zero flow level (Fig. 1). In this range, the respiratory system is totally unloaded. Therefore, a resonant oscillation occurs. Using the $\dot{V}$ signal, $\mathrm{f}_{\mathrm{r}}$ is calculated by the ventilator's computer.

Animal model. Ten healthy adult rabbits weighing $4.4 \pm 0.5$ $\mathrm{kg}$ (range $3.8-5.1 \mathrm{~kg}$ ) were studied. Anesthesia was induced with an i.v. bolus injection of $30 \mathrm{mg} / \mathrm{kg}$ sodium pentobarbital and maintained with intermittent doses of $2-5 \mathrm{mg} / \mathrm{kg}$ every $60 \mathrm{~min}$. Infusion fluids were given at $3 \mathrm{~mL} / \mathrm{kg} / \mathrm{h}$ i.v. Tracheostomy was performed on each animal, and the trachea was cannulated with a $3.5-\mathrm{mm}$ inner diameter uncuffed ETT (length $185 \mathrm{~mm}$ ) that was secured in place by a peritracheal ligature. The animal was then connected to the ventilator in the supine position and ventilated conventionally with $100 \%$ oxygen, rate 60 cycles per min, inspiratory/expiratory ratio $1: 1$. Tidal volume was adjusted

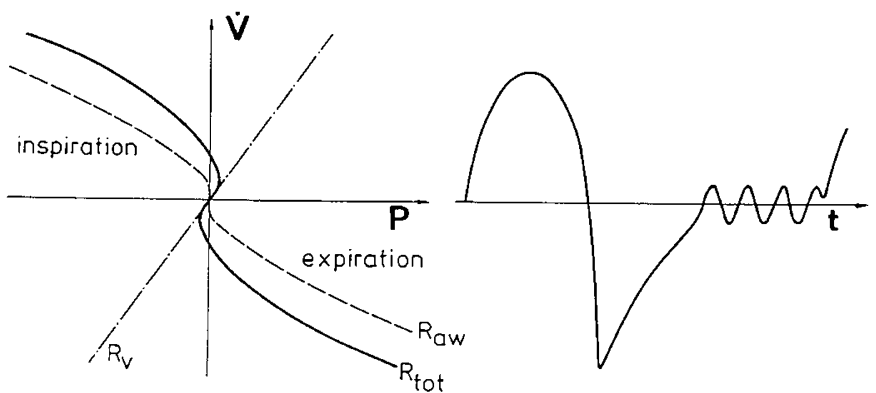

Fig. 1. Qualitative pressure $(P)$-flow $(\dot{V})$ characteristics (left panel) illustrating the effect of a negative ventilator resistance $\left(R_{v}\right)$. The slope of a $\mathrm{P}-\dot{\mathrm{V}}$ characteristic, given by the quotient $\Delta \mathrm{P} / \Delta \dot{\mathrm{V}}$, represents resistance. Resistance of the airways $\left(R_{a w}\right)$ is curvilinear. Against this, the ventilator's $\mathrm{P}-\dot{\mathrm{V}}$ relationship is linear with an inverse, i.e. negative slope. The total resistive load $\left(R_{t o t}\right)$ placed on the animal's spontaneous breathing effort equals the sum of $R_{a w}$ and $R_{v} . R_{t o t}$ is smaller than $R_{a w}$ and becomes negative around zero flow range. A scheme of a spontaneous breath over time $(t)$ is projected on the righthand side of the diagram. When expiratory airflow slowly returns to zero flow level, the system starts to swing at $f_{r}$ within a flow range characterized by negative $R_{\text {tot }}$.
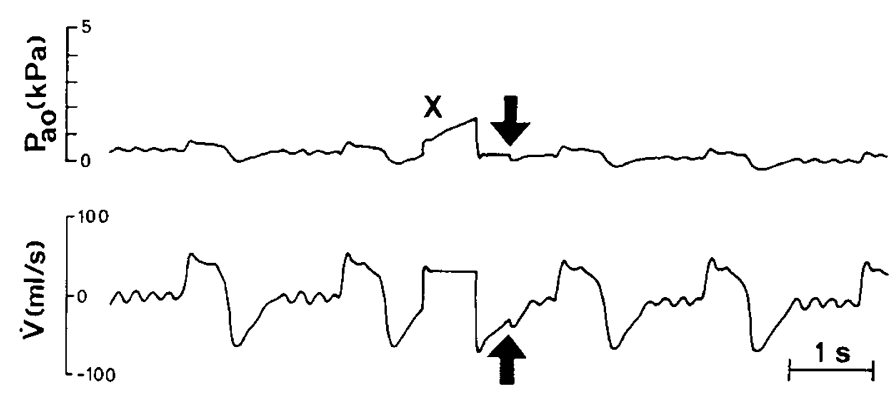

Fig. 2. Replica of original tracings. Intermittent mandatory ventilation with NVR mode. During spontaneous breathing, the $\mathrm{P}_{\text {ao }}$ varies around a baseline level of CPAP. Inspiratory air flow $(\dot{V})$ is above and expiratory $\dot{V}$ is below zero flow line. $P_{a o}$ increases with inspiratory $\dot{V}$ and decreases with expiratory $\dot{V}$. There is no phase lag between $\dot{V}$ and $P_{a o} . A$ resonant oscillation occurs at end expiration. The mandatory breath $(X)$ is not synchronized with the spontaneous breathing activity. It starts at a substantial expiratory flow of a spontaneous cycle. After the initial resistive jump, $\mathrm{P}_{\mathrm{a}}$ rises linearly during constant flow inflation. This segment was used in our study for determination of inflation compliance. For passive deflation, the ventilator switches then to a constant expiratory positive pressure level. Before reaching zero flow level, the NVR mode is added (arrows), resulting in an accelerated expiration (time constant shortened) and shallow swinging.

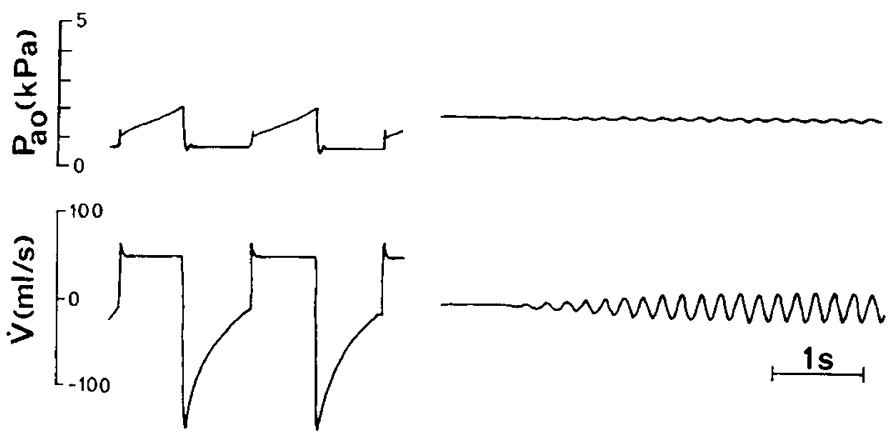

Fig. 3. Representative original tracings after pharmacologic relaxation. It is possible to calculate inflation method compliance during CMV at constant inspiratory flow (left panel). For determination of $f_{r}$, CPAP mode was commanded (right panel). A $\mathrm{P}_{\text {ao }}$ level previously characterized by linear increment during constant flow inflation was used. A permanent oscillation settled after introduction of negative ventilator resistance.

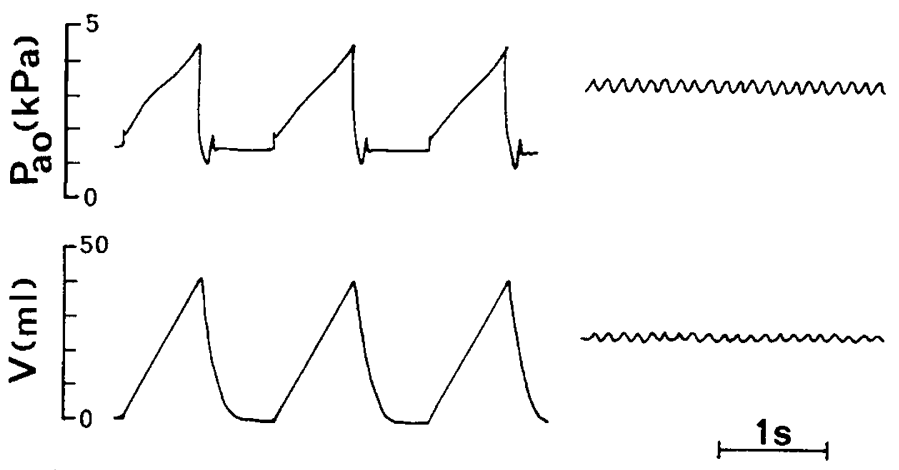

Fig. 4. Original tracings after surfactant depletion. Instead of the flow signal, its integral tidal volume $(V)$ is recorded together with $\mathrm{P}_{\mathrm{ao}}$. In comparison with Figures 2 and 3, respiratory system compliance is severely decreased. This corresponds with an elevated $f_{r}$ (right panel).

to maintain normocarbia. Rectal temperature was monitored and regulated between 38 and $39^{\circ} \mathrm{C}$ using a warming pad. An arterial line was inserted through the left carotid artery for intermittent determination of arterial blood gases by a $\mathrm{pH} /$ blood gas system (Radiometer, Copenhagen, Denmark). The animals were then allowed to breathe spontaneously via the ventilator 


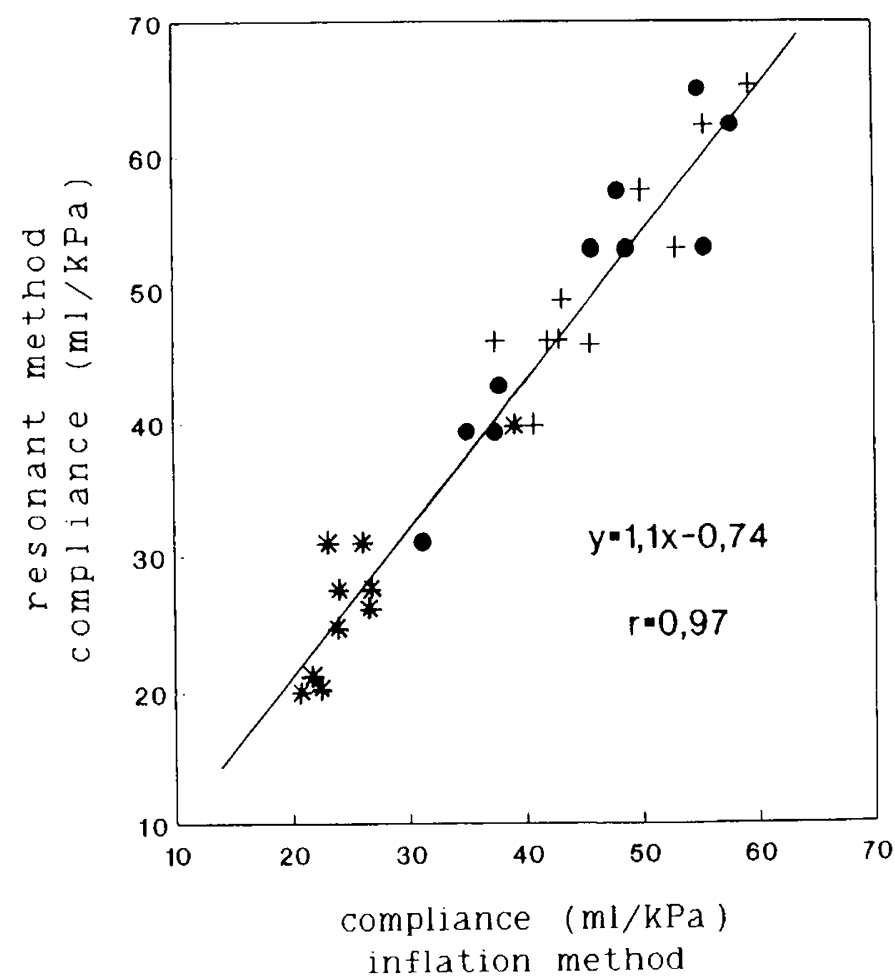

Fig. 5. Identity plot between total respiratory system compliance measured with the inflation method and corresponding values calculated from $\mathrm{f}_{\mathrm{r} .}$. Filled circles, values measured during spontaneous breathing; crosses, after pancuronium relaxation; asterisks, after surfactant removal

Table 1. $C_{i}$ and $C_{r}{ }^{*}$

\begin{tabular}{lccc}
\hline & $\begin{array}{c}\text { Before } \\
\text { relaxation }\end{array}$ & $\begin{array}{c}\text { After } \\
\text { relaxation }\end{array}$ & $\begin{array}{c}\text { Surfactant } \\
\text { depleted }\end{array}$ \\
\hline $\mathrm{C}_{\mathrm{j}}(\mathrm{mL} / \mathrm{kPa})$ & $45.3 \pm 9.4$ & $47 \pm 7.1$ & $25.5 \pm 5.2 \dagger$ \\
$\mathrm{C}_{\mathrm{r}}(\mathrm{mL} / \mathrm{kPa})$ & $49.5 \pm 11 \ddagger$ & $51 \pm 8.2 \ddagger$ & $27 \pm 5.9 \dagger$ \\
$\mathrm{f}_{\mathrm{r}}\left(\mathrm{min}^{-1}\right)$ & $274 \pm 33.2$ & $267 \pm 21.4$ & $371 \pm 39.5 \dagger$ \\
\hline
\end{tabular}

${ }^{*} \mathrm{C}_{\mathrm{r}}$ was calculated from $\mathrm{f}_{\mathrm{r}}$ of the respiratory system. Each of 10 rabbits was examined before and after pharmacologic relaxation and after washout of surfactant. Values are given as mean $\pm S D$.

$\dagger$ Significantly different from values before and after relaxation $(p<$ $0.05)$.

$\ddagger$ Significantly different from $C_{\mathrm{i}}(p<0.05)$.

while on intermittent mandatory ventilation mode. The volumecontrolled cycles were used for measurement of $C_{i}$. Only relaxed inflations were accepted for evaluation. Additional spontaneous breathing activity during the mechanical inflations could be easily detected by on-line inspection of $\dot{\mathrm{V}}$, volume, and $\mathrm{P}_{\mathrm{a}}$ records (8). Mean values of at least 10 measurements were used for evaluation. NVR mode was superimposed on backup CPAP during spontaneous breathing between mechanical breaths. Resonant oscillations occurred during the periods of near zero flow at end expiration. Calculation of $\mathrm{C}_{\mathrm{r}}$ was based on the frequency of these oscillations (Fig. 2). Afterward, neuromuscular paralysis was initiated and maintained with i.v. pancuronium bromide $(0.2 \mathrm{mg} / \mathrm{kg} / \mathrm{h})$. Compliance measurements were repeated during CMV. A CPAP period with NVR was temporarily set to determine $f_{r}$ (Fig. 3). Pulmonary lavage was then performed to remove surfactant according to the standard method (12) six to 10 times over a 20 - to 30 -min period with normal saline at a pressure not exceeding $4 \mathrm{kPa}$ (approximately $100 \mathrm{~mL}$ each wash). Adequate pulmonary lavage was considered to have been achieved if the arterial oxygen tension on CMV was $13 \mathrm{kPa}$ or less after a 15 to $30-\mathrm{min}$ postlavage control period. Mean airway pressure was elevated after the second or third lung wash. Compliance determinations were repeated in the same manner after the pulmonary lesion was established. $C_{i}$ and $f_{r}$ measurements were performed at the same airway pressure range (Fig. 4).

Calculation of $C_{r}$. The I of the ETT used in these experiments was calculated from the tube's dimensions according to equation 3 . Gas density of pure oxygen at $33^{\circ} \mathrm{C}$ is $1.28 \mathrm{~kg} / \mathrm{m}^{3}$. Thus, I had the value $0.0245 \mathrm{kPa} \cdot \mathrm{s}^{2} / \mathrm{L}$. Based on equation 2 , this yields $\mathrm{C}_{\mathrm{r}}$ when $f_{r}$ is known.

Statistics. The paired $t$ test was used to test for significant differences in mean values. All $p$ values of $<0.05$ were considered to represent significant differences. Data are presented as mean \pm 1 SD. The least squares method was used to obtain the best fitting line for Figure 1.

\section{RESULTS}

Three pairs of compliance values were taken into consideration from each animal: before relaxation, after relaxation, and after surfactant depletion. There was a significant linear correlation between $C_{i}$ and $C_{r}$ values $(p<0.0001)$ with the regression line lying close to the identity line (Fig. 5 ).

$\mathrm{C}_{\mathrm{r}}$ exceeded the values obtained by the inflation method significantly before and after pancuronium. The difference between $C_{r}$ and $C_{i}$ did not reach the level of significance after surfactant removal (Table 1).

Pharmacologic muscle relaxation resulted in a slight but nonsignificant increase in $C_{i}$, whereas the drop in $C_{i}$ values after surfactant depletion was highly significant. The same holds true for $C_{r}$ values, which reflect the variations in $f_{r}$.

\section{DISCUSSION}

It has been shown in our study that total respiratory system compliance, when calculated from $\mathrm{f}_{\mathrm{r}}$, is virtually identical to the $\mathrm{C}_{\mathrm{i}}$ in tracheotomized rabbits.

This confirmed an important assumption underlying this approach for calculation of $\mathrm{C}_{\mathrm{r}}$ - that the $\mathrm{I}$ of the ETT constitutes the overwhelming part of the combined ventilator-ETT-lung system. Moreover, it is possible to conclude that oscillations induced by resistive unloading with the NVR mode are indeed oscillations at $\mathrm{f}_{\mathrm{r}}$. Thereby, NVR has proved to be an elegant method for determination of the $f_{r}$ of the combined ventilatorETT-respiratory system in healthy and surfactant-depleted lungs as well.

That $C_{r}$ values slightly exceeded $C_{i}$ probably reflects the fact that the total $\mathrm{I}$ is a little bit higher than that of the ETT alone, which was only taken into account for calculation of $C_{r}$ values. The ventilator itself has an inertial property in addition to the I of the bronchial tree. This has not yet been determined quantitatively and remains to be clarified.

The internal compressible volume of the infant ventilator used in our study amounts to $2 \mathrm{~mL}$ (4). Compliance of that volume is $2 \mathrm{~mL} / 100 \mathrm{kPa}(20 \mu \mathrm{L} / \mathrm{kPa})$. Therefore, the impact of the ventilator's compliance on the $f_{r}$ of the combined ventilatorETT-lung system can be neglected.

The theoretical concept used is only valid for a homogeneous lung model. Such an oversimplified model neglects the nonuniform regional compliances that exist, especially in injured lungs. A multicompartmental lung is supposed to have regional differences in $\mathrm{f}_{\mathrm{r}}$. Therefore, the $\mathrm{C}_{\mathrm{r}}$ method as described here should be used with caution until more detailed data are available from more complex models and a broad spectrum of clinical situations. However, we have shown that at least the rabbit plus ventilator system before and after lung lavage behaves like a simple, first order resistor-capacitance-inductor system. When measured with the NVR mode, we found defined $f_{r}$ that fit the predictions based on the homogeneous model.

In comparison with conventional methods for determination of total respiratory system compliance in intubated infants, as the inflation or the occlusion method (13), our approach offers the following advantages: 1) It works not only after putting 
respiratory muscles at rest, but also when there is spontaneous breathing activity; 2) An "intrinsic positive end expiratory pressure" leads to an error in the occlusion method (14), but is irrelevant for the resonant method; and 3) The occlusion method requires two single points for measurement of $\mathrm{P}_{\mathrm{a} o}$ and is therefore unable to detect inconstancies of the compliance over this relatively large $P_{a o}$ range (13). Against this, it is possible to evaluate the compliance course in a $\mathrm{P}_{\mathrm{ao}}$ range by varying the preset baseline $\mathrm{P}_{\mathrm{ao}}$ level in a ramp-like manner and recording the effect on $f_{r}$.

On the other hand, a ventilator system with the capability of resistive unloading is necessary to use this $f_{r}$ method. This might be considered a drawback as such ventilators are not yet commercially available.

\section{REFERENCES}

1. Schaller P 1982 Patent "Beatmungsgerät" DD A 61 M 16/00:212186

2. Schaller P 1983 Patent "Beatmungsgerät" DD A 61 H 31/00:221364

3. Schaller P 1987 Ein Druck-Volumenstrom-Generator zur Erzeugung von Ventilationsmustern für die Säuglingsbeatmung. Dresden Technical University, Dresden, East Germany. Dissertation.

4. Schulze A, Schaller P, Gehrhardt B, Mädler HJ, Dinger J, Gmyrek D, Winkler U, Nitzsche H, Mehler HJ 1989 High frequency oscillatory and conventional mechanical ventilation in experimental surfactant deficiency: a study using a new infant ventilator technique. Z Erkr Atmungsorgane 172:272-281
5. Rohrer F 1915 Der Strömungswiderstand in den menschlichen Atemwegen und der Einflu $\beta$ der unregelmäßigen Verzweigungen des Bronchialsystems auf den Atmungsverlauf in verschiedenen Lungenbezirken. Arch Gesamte Physiol Mens Tiere (Pfluegers) 162:225-238

6. Schaller P, Schulze A 1989 Patent "Verfahren und Anordnung zur Bestimmung der Dehnbarkeit des Atemtraktes (Compliance)" DD A 61 H 31/00:272413

7. Suratt PM, Owens DH, Kilgore WT, Harry RR, Hsiao HS 1980 A pulse method of measuring respiratory system compliance. J App Physiol 49:11161121

8. Suratt PM, Owens DH 1981 A pulse method of measuring respiratory system compliance in ventilated patients. Chest 80:34-38

9. Bates JHT, Rossi A, Milic-Emili J 1985 Analysis of the behavior of the respiratory system with constant inspiratory flow. J Appl Physiol 58:18401848

10. Schaller P, Mädler HJ, Schulze A, Böhme B, Leupold W 1985 Ein LamellenSpirorezeptor für die Pneumotachographie bei Frühgeborenen und Säuglingen. Z Klin Med 40:947-949

11. Schaller P, Mädler HJ, Schulze A, Gmyrek D 1989 Optimal design of a pneumotachograph head with respect to dead space and resistance. Pediatr Res 26:517(abstr)

12. Lachmann B, Robertson B, Vogel J 1980 In vivo lung lavage as an experimental model of the respiratory distress syndrome. Acta Anaesthesiol Scand 24:231236

13. Rossi A, Gottfried SB, Higgs BD, Zocchi L, Grassino A, Milic-Emili J 1985 Respiratory mechanics in mechanically ventilated patients with respiratory failure. J Appl Physiol 58:1849-1858

14. Rossi A, Gottfried SB, Zocchi L, Higgs BD, Lennox S, Calverley PMA, Begin P, Grassino A, Milic-Emili J 1985 Measurement of static compliance of the total respiratory system in patients with acute respiratory failure during mechanical ventilation. The effect of intrinsic positive end-expiratory pressure. Am Rev Respir Dis 131:672-677 